\title{
Children's vomiting following posterior fossa surgery: $A$ retrospective study
}

\author{
Susan M Neufeld ${ }^{* \dagger 1}$, Christine V Newburn-Cook ${ }^{\dagger 1}$, Donald Schopflocher ${ }^{\dagger 1}$, \\ Belinda Dundon ${ }^{\dagger 2}$, Herta $\mathrm{Yu}^{\dagger 2}$ and Jane E Drummond ${ }^{\dagger 1}$
}

\author{
Address: ${ }^{1}$ Faculty of Nursing, University of Alberta, Edmonton, Canada and ${ }^{2}$ Hospital for Sick Children, Toronto, Ontario, Canada \\ Email: Susan M Neufeld* - cgrapel@shaw.ca; Christine V Newburn-Cook - christine.newburn-cook@ualberta.ca; \\ Donald Schopflocher - donald.schopflocher@ualberta.ca; Belinda Dundon - 3kiddies@gmail.com; Herta Yu - herta.yu@sickkids.ca; \\ Jane E Drummond - jane.drummond@ualberta.ca \\ * Corresponding author †Equal contributors
}

Published: 13 July 2009

BMC Nursing 2009, 8:7 doi:10.1186/1472-6955-8-7

This article is available from: http://www.biomedcentral.com/l472-6955/8/7

(c) 2009 Neufeld et al; licensee BioMed Central Ltd.

This is an Open Access article distributed under the terms of the Creative Commons Attribution License (http://creativecommons.org/licenses/by/2.0), which permits unrestricted use, distribution, and reproduction in any medium, provided the original work is properly cited.
Received: 10 December 2008

Accepted: 13 July 2009

\begin{abstract}
Background: Nausea and vomiting is a problem for children after neurosurgery and those requiring posterior fossa procedures appear to have a high incidence. This clinical observation has not been quantified nor have risk factors unique to this group of children been elucidated.

Methods: A six year retrospective chart audit at two Canadian children's hospitals was conducted. The incidence of nausea and vomiting was extracted. Hierarchical multivariable logistic regression was used to quantify risk and protective factors at 120 hours after surgery and early vs. late vomiting.

Results: The incidence of vomiting over a ten day postoperative period was $\mathbf{7 6 . 7 \%}$. Documented vomiting ranged from single events to greater than 20 over the same period. In the final multivariable model: adolescents (age 12 to <17) were less likely to vomit by 120 hours after surgery than other age groups; those who received desflurane, when compared to all other volatile anesthetics, were more likely to vomit, yet the use of ondansetron with desflurane decre kelihood. Children who had intraoperative ondansetron were more likely to vomit in the final multivariable model (perhaps because of its use, in the clinical judgment of the anesthesiologist, for children considered at risk). Children who started vomiting in the first 24 hours were more likely to be school age (groups 4 to $<7$ and 7 to $<12$ ) and receive desflurane. Nausea was not well documented and was therefore not analyzed.
\end{abstract}

Conclusion: The incidence of vomiting in children after posterior fossa surgery is sufficient to consider all children requiring these procedures to be at high risk for POV. Nausea requires better assessment and documentation.

\section{Background}

The successful management of nausea and vomiting is an important component in the care of children after surgery. Postoperative nausea and vomiting (PONV) may cause discomfort and distress, put pressure on surgical incisions, cause dehydration and electrolyte imbalance, delay recovery, and prolong hospitalization [1,2]. Children are at high risk for experiencing PONV [3-5], and estimates of 
postoperative vomiting (POV) for children requiring craniotomy have been as high as $66 \%$ [6]. The effects of increased intracranial pressure during retching and vomiting may be especially problematic after craniotomy [7]. Therefore, children after craniotomy may be at particular risk for experiencing PONV that result in suffering and other negative outcomes.

Tramer [8] describes three rules of practice to ensure optimal management of PONV: identify those at risk using predictive factors; modify anaesthesia techniques to keep the baseline risk as low as possible; and administer antiemetics rationally with consideration to their efficacy, additive properties, and adverse effects. Of these, Tramer concedes that knowledge of risk factors remains an underresearched area, especially for children. In one of the few multivariable studies of predictive factors of POV in children [9], the combination of the following factors could be used to determine a child's risk of POV after surgery: history of POV in the child or PONV in father, mother or siblings; age over three years; length of surgery over thirty minutes; and strabismus surgery. The results of this study were further validated in a separate group of children [10] and were predictive of POV even when strabismus surgery was not in the prognostic model. These studies did not have the participation of children requiring craniotomy. However, if the prognostic models were used to predict POV in children after craniotomy, age and history of POV or PONV in father, mother, or siblings would be the only variables that could be used to predict POV.

POV and/or PONV after craniotomy in children have not been well described in the literature. Two small randomized controlled trials of ondansetron, a $5-\mathrm{HT}_{3}$ receptor antagonist, have estimates of 24 hour POV in children after craniotomy that range from $24 \%$ [11] to $66 \%$ [6], whereas PONV in older children was estimated at $32 \%$ [11]. Although some clinicians believe that the use of prophylactic anti-emetics decreases the incidence of POV in these children, neither study could show efficacy for intraoperative administration of ondansetron in reducing children's POV by 24 hours. Subramaniam et al. [10] could not show evidence for an extra scheduled postoperative dose of ondansetron either. Finally, intermittent dosing of any class of anti-emetics does not appear to have been studied in this patient population. In order to effectively design such studies, knowledge of the incidence of PONV and associated risk and protective factors must be first established to know the extent of the problem and ensure that the children at highest risk are targeted for prophylaxis.

Children who appear to be at high risk for nausea and vomiting are those who require posterior fossa craniotomy. Posterior fossa surgery takes place below the tento- rium cerebelli in the posterior cranial fossa. The posterior cranial fossa houses structures that include: the cerebellum; brainstem; and cranial nerves III-XII. Although the reticulospinal tracts, diencephalon, limbic system, and discrete areas of the cerebral hemispheres may all be involved in nausea, retching, and vomiting, the coordination of the autonomic changes associated with retching and vomiting occurs at the level of the medulla oblongata in the posterior fossa [12-14]. Thus, from an anatomical perspective, procedures that are proximal to this area may place patients at especially high risk for vomiting. The aforementioned studies in children after craniotomy $[6,11]$ have been too small to allow this conclusion to be drawn, but studies in adults suggest that posterior fossa procedures are related to greater postoperative nausea (PON) [7] and PONV [15-17] when compared to supratentorial procedures. However, Quiney and colleagues [18] prospectively examined nausea and vomiting in 52 adults and children (aged 8-74) after craniotomy and found that $37 \%$ of participants experienced severe nausea or vomiting, while $35 \%$ experienced nausea at the end of the 24 hour period. These authors could not find any relationship between location of surgery and symptoms; however, their small sample size limits the validity of this finding.

Children who require craniotomy form a heterogeneous group. By specifically studying children after posterior fossa surgery, the research questions can be focused on the unique risk and protective factors for PONV for this group of children, while limiting the heterogeneity in the sample. This approach has shown success in determining risk and protective factors specific to the location of the neurosurgery in adult studies [19-21]. Thus, the purpose of this study was to describe PONV in children requiring posterior fossa surgery, to explore risk and protective factors for PONV, and to examine the relationship of PONV to adverse outcomes. Results could then be used to guide the design of future studies and provide the rationale for implementing improvements to clinical practice.

\section{Methods}

The hospital charts of children who required posterior fossa surgery at two Canadian children's hospital sites, the Stollery Children's Hospital in Edmonton and the Hospital for Sick Children in Toronto, were reviewed for the study. A retrospective study design was chosen as an efficient and cost effective way to describe nausea and vomiting in this group of children. Specifically, for the acute postoperative period, we sought to determine:

1) The cumulative incidence of nausea and vomiting by: hours 4,8 , and 24; and during subsequent 24 hour periods. 
2) The frequency distribution of number of days that nausea and vomiting were experienced.

3) The frequency distribution of number of vomiting events.

4) The significant risk and protective factors for nausea and vomiting.

5) The co-morbidities that children with nausea and vomiting experience.

\section{Sample Selection \& Sample Size Estimation}

Following institutional ethical review and administrative approval at each centre, all patients under age seventeen who had posterior fossa surgery between March 1, 2001 and March 1, 2007 were identified for chart retrieval through two separate paediatric neurosurgeons' databases (Stollery Children's Hospital) and a central paediatric neurosurgery database (Hospital for Sick Children). The upper limit for age was determined by the age of qualification for admission to both children's hospitals. Fourth ventricular shunt procedures, operations without dural openings (outside the brain), surgery for traumatic brain injury, and children requiring prolonged intubation (greater than 48 hours) were excluded. If more than one posterior fossa procedure was required for a child over the study period, the earliest one was included in the study. Prospectively, we estimated data from two sites to involve approximately 300 children. This would allow for an estimation of incidence within a $6 \%$ margin of error [22]. It would also allow for a multivariable analysis of 10-15 variables if the incidence of an outcome ranged from 30$70 \%$, which would allow for one independent variable per ten outcomes [23].

\section{Data Collection Procedures}

A case report form was developed specifically for the study in collaboration with a paediatric educator in surgery, a neurosurgeon, and clinical nurse specialists/advanced nurse practitioners in children's neurosurgery. Data were collected by review of the child's in-patient chart. The data collection period extended over the course of a child's neurosurgical postoperative hospital stay, up to ten days. Thus, data collection ended when the child went home, was transferred from neurosurgical care to rehabilitation care (i.e. to a rehabilitation hospital or rehabilitation unit), was transferred from neurosurgery care to oncology care for further treatments, or at 240 hours after the recorded time that the anaesthetic was finished. The first ten postoperative days were chosen by the study team to ensure that an adequate length of time was captured for the exploratory analysis. The final outcomes for analysis of risk and protective factors were determined based on these exploratory results.
One nurse with paediatric neurosurgical experience at each site collected data. To ensure reliability, the two data collectors trained on ten charts. Revisions to the data collection form were then made as necessary. For example, the child's activity and diet at each time period were initially part of the case report form. Due to gaps in charting, these data could not be collected reliably. Once the case report was finalized, each person then reviewed the same five randomly selected charts to establish inter-rater reliability: $100 \%$ inter-rater reliability was achieved for the main study outcomes, independent variables and adverse events. Weekly contact was maintained between the two sites to discuss issues that arose during data collection.

\section{Measurement}

PONV covers one or more of three symptoms: nausea; retching; and vomiting [24]. Nausea is the unpleasant sensation of the urge to vomit that occurs along with neurological changes such as excessive salivation and swallowing [25]. Each time nausea was charted in the nurses' notes, it was recorded on the study case report form. Documented children's statements or behaviours that referred to nausea, such as states that he feels "like throwing up" or "appears nauseous," were also included.

Retching is the first phase of vomiting [12] and is commonly defined as an unproductive attempt to vomit [25]. Vomiting is the forceful expulsion of stomach contents through the mouth that involves coordinated autonomic processes in the brain and gut [12]. Because of their similar physiology, retching and vomiting should be considered together in the data analysis, whereas nausea should be considered separately [26]. To screen for retching and vomiting events (POV), the post-anaesthesia recovery room record was first reviewed, followed by the in and out flow sheets. The time of the event was noted. The nurses' notes and assessment flow charts were then read for further events, for more accurate time of the event if it corresponded to the in-and-out flow sheets, and to screen for retching episodes. If retching and vomiting were documented at the same time, they were considered one event. The medication administration records were reviewed and anti-emetic administration was noted. If an anti-emetic was administered, the nurses' notes were reviewed a second time to look for a documented retching or vomiting event around the time of the administration of the antiemetic. Administration of an anti-emetic was not considered indication of nausea, retching or vomiting.

Data on potential risk factors were collected from the admission records, physician notes, anaesthesia records, operative reports, and medication flow sheets. This data included age of child, gender, presenting symptoms, type of surgery, length of surgery, use of intraoperative dexamethasone and/or ondansetron (administration at any time 
after induction), and type of anaesthetic. For analysis, age was examined in quartiles rounded to the year: 0 to $<4 ; 4$ to $<7 ; 7$ to $<12$; and 12 to $<17$. A number of variables were dichotomized for analysis. The use of desflurane has been shown to be a risk factor in adults requiring retromastoid craniectomy, compared to other volatile anaesthetics [20]. We therefore examined the use of desflurane (alone or in combination with another volatile anaesthetic) compared to a grouping of all other volatile anaesthetics. This was the only variable with missing values $(\mathrm{n}=13$; either undocumented in the chart or illegible) and, due to the likelihood that the missing value was not desflurane, we included the missing values in the "other" category (the mode was isoflurane). The use of nitrous oxide, a well known risk factor for PONV [24], was rarely documented for induction and not used for maintenance, and therefore was not assessed as in intraoperative risk factor. Intraoperatively, ondansetron was the only anti-emetic used, and dexamethasone the only steroid.

Finally, Potential co-morbidities, including development of a pseudomeningocele, wound failure or cerebral spinal fluid leak through the incision, and wound infection, were noted by examining the nursing notes, physician notes, discharge summary, and/or reasons for readmission to the neurosurgical service. Reports of postoperative imaging studies were also reviewed for possible documentation of a pseudomeningocele.

\section{Data Analysis}

Data analysis was conducted using SPSS Version 15.0 software. Demographic and study variables were summarized using descriptive statistics that were appropriate to their level of measurement. Cumulative incidence (number of children with at least one recorded event by the specified time period/total number of children in the study) was used to calculate outcomes at: 4,8 , and 24 hours, and for subsequent 24 hour periods until the end of the study period. The number of days that an outcome was experienced was calculated by subtracting the time of the first recorded event from the last recorded event, and was summarized using a frequency distribution. A frequency distribution was also used for counts of recorded events.

Univariate logistic regression was first conducted to examine the relationships between each variable and the outcomes. Additionally, the clinical plausibility of an interaction effect of ondansetron and dexamethasone was tested using two steps. In the first step, the adjusted odds ratios of ondansetron and dexamethasone were estimated using multivariable logistic regression. Then, the interaction term of ondansetron and dexamethasone was entered in the second step.

The univariate analysis was followed by multivariable logistic regression to examine important risk and protec- tive factors for the outcomes while controlling for other variables. To determine confounding effects, variables were entered into the multivariable model in an a-priori determined, hierarchical fashion based on sequential events (Figure 1). If a variable grouping changed the regression coefficients of a previously entered statistically significant variable by $\geq 15 \%$, it was considered to be confounding (i.e., related to both the variable and the outcome). Conversely, if a variable that was not previously statistically significant became so with a change of $\geq 15 \%$, that grouping was also considered confounding. Individual variables within that grouping were then tested individually to examine their relationship to the confounded variable.

In the final step, plausible interactions of statistically significant variables were tested to determine if any moderating effects were present (i.e., that the relationship that one variable has with an outcome changes depending on the value of another variable). The clinical plausibility of dexamethasone and ondansetron administered together vs. either drug administered alone were again tested using

\section{Site}

2. Child Characteristics

- Age

- Gender

- Required Surgery

\section{Presenting Symptoms (Vomiting)}

\section{Intraoperative Care}

- Use of Desflurane

- Administration of Dexamethasone

- Administration of Ondansetron

- Length of Surgery

\section{Significant Interaction Terms*}

\section{Figure I}

Hierarchical model for variable entry into multivariable analysis. *Interaction terms tested will be intraoperative ondansetron and dexamethasone as well as combinations of plausible statistically significant variables from the multivariable model. 
an interaction term in the larger multivariable models at this time. Only statistically significant interactions were included in the final model. Multicollinearity, associations among the independent variables in the model, was reviewed by looking for correlations above 0.8 between any two variables.

To finish the analysis, cross tabulations were used to examine the relationship between the final outcomes and other adverse events. The phi statistic ( $\varphi$ ) for nominal by nominal variables was used to summarize these relationships. This statistic was also used to examine relationships between categorical confounding variables, whereas a Pearson's correlation (r) was used for continuous variables.

\section{Results \\ Sample Characteristics}

Table 1 contains a description of the study sample. A total of 249 children met the criteria for the study, from 329 potential candidates who were identified from three neurosurgery databases. Of those excluded, 23 were wrongly coded as posterior fossa procedures in the database, 22 were intubated for more than 48 hours, 13 had Chiari I bony decompressions without a dural opening, 13 had a supratentorial component to their surgery (other than $\mathrm{EVD} /$ shunt insertion), 7 had ventriculo-peritoneal shunt procedures only, and 2 had no corresponding hospital record.

\section{Description of PON, POV and PONV}

The cumulative incidence of PON, POV and PONV over the first ten days is presented in Table 2. As shown in this table, there was a discrepancy in the documentation of PON and POV. Because we felt that PON was not reliably measured and documented, the remainder of the data analysis was refocused to examine POV. The frequency distribution of the time from first recorded POV to last recorded POV is presented in Figure 2. The frequency distribution of POV events that were recorded over the study period is shown in Figure 3. These figures indicate that there was considerable variation in length of time that children experienced vomiting as well as number of recorded events. Close to $47 \%$ of children experienced vomiting over a time course greater than 24 hours, while $20 \%$ continued to vomit over a time course greater than 120 hours. Recorded events, shown in Figure 3, show a positively skewed distribution with $23 \%$ children with no events, $36 \%$ of children with only one to three recorded events, and $41 \%$ with over three events.

\section{Analysis of risk and protective factors}

Based on the initial exploratory data analysis, we decided to examine the risk and/or protective factors for two outcomes: POV in the first 120 hours (the acute postoperative period), and early (an event recorded by 24 hours or less) compared to late POV (the first event occurring after 24 hours up to 120 hours). The decision to make the cut-off for the acute postoperative period 120 hours, despite data collection that went up to 240 hours, was to control for confounding factors such as early discharge, the requirement for sedation for procedures or tests, or the need for further surgery that were emerging in the data after 120 hours. After data collection, it was clear that some potential risk factors could not be reliably collected due to lack of documentation or inconsistent documentation. These included: a history of PONV in the child or family member; a history or motion sickness; and pain rating.

The initial univariate logistic regressions (Table 3 ) indicated that only Chiari I Malformation surgery was a statistically significant risk factor for POV by 120 hours. Additionally, children in the two middle age quartiles (4 to $<7$ and 7 to $<12$ ) showed lower odds of late vomiting compared to early. Thus, while overall these children did not have greater odds of vomiting, they were more likely to have early vomiting than the other age groups. When testing for an interaction effect for ondansetron and dexamethasone, the first step showed that, when controlling for dexamethasone, ondansetron became positively predictive of POV by 120 hours. The second step showed that the interaction effect (i.e. an enhanced effect of both drugs together) of ondansetron and dexamethasone was not significant.

In the first multivariable analysis (Table 4), controlling for the other variables in the model, children with any use of desflurane (compared to the grouping of children who received either sevoflurane, isoflurane, or a combination of these), who received intraoperative ondansetron, who required Chiari I malformation surgery or who had surgery at the Hospital for Sick Children site had an increased likelihood of vomiting by 120 hours. Conversely, children in the fourth age quartile $(12$ to $<17)$ were less likely to vomit by 120 hours. Finally, the significant interaction term indicated that intraoperative ondansetron moderated the likelihood of vomiting with desflurane by 120 hours. Thus, those children who received desflurane were less likely to vomit if given intraoperative ondansetron than were those who received desflurane without receiving intraoperative ondansetron.

There were a number of variables which appeared to confound the effects of previously entered variables in the model. When the factor of whether or not a child presented with vomiting was added (Model 3), the odds ratio for POV by 120 hours for Chiari I surgery increased. A greater proportion of children with brain tumours presented with vomiting than those with Chiari I malformations or other procedures ( $72 \%$ vs. $5 \%$ vs. $7 \%$, phi statistic 
Table I: Sample characteristics

\begin{tabular}{|c|c|}
\hline Parameter & \\
\hline Number of Patients & 249 \\
\hline \multicolumn{2}{|l|}{ Site $n(\%)$} \\
\hline Stollery Children's Hospital & $55(22.1 \%)$ \\
\hline Hospital for Sick Children & $194(77.9 \%)$ \\
\hline Length of hospital stay in days (Mean $\pm S D$, Range) & II ( $( \pm 21,2-305)$ \\
\hline Age in years (Mean $\pm S D$, Range) & $7.6 \pm 4.4,0.3--16.8$ \\
\hline \multicolumn{2}{|l|}{ Age in Quartiles n(\%) } \\
\hline 0 to $<4$ years & $65(26.1 \%)$ \\
\hline 4 to $<7$ years & $61(24.5 \%)$ \\
\hline 7 to $<12$ years & $75(30.1 \%)$ \\
\hline 12 to $<17$ years & 48 (19.3\%) \\
\hline Male: Female (Ratio \%) & $\mid 28$ (5I.4\%): $12 \mid(48.6 \%)$ \\
\hline \multicolumn{2}{|l|}{ Surgery $n(\%)$} \\
\hline Brain Tumour & $153(61.4 \%)$ \\
\hline Chiari I Malformation & $81(32.5 \%)$ \\
\hline Other & $15(6.0 \%)$ \\
\hline Chiari II Malformation & $7(2.8 \%)$ \\
\hline Vascular Malformation & $4(1.6 \%)$ \\
\hline Cyst or Aspiration of Pus & $4(1.6 \%)$ \\
\hline Presenting with vomiting $\mathrm{n}(\%)$ & $115(46.2 \%)$ \\
\hline Preoperative Dexamethasone $\mathrm{n}(\%)^{1}$ & $136(54.6 \%)$ \\
\hline Intraoperative Ondansetron & $117(47.0 \%)$ \\
\hline Without Dexamethasone & $47(18.9 \%)$ \\
\hline Intraoperative Dexamethasone & $|3|(52.6 \%)$ \\
\hline Without Ondansetron & $61(24.5 \%)$ \\
\hline Intraoperative Ondansetron and Dexamethasone & $70(28.1 \%)$ \\
\hline No intraoperative anti-emetic & $71(28.5 \%)$ \\
\hline Length of surgery in hours (Mean $\pm S D$, Range) & $5: 01 \pm 2: 10(1: 39-17: 56)$ \\
\hline Length of anaesthesia in hours (Mean $\pm S D$, Range) & $6: 22 \pm 2: 20(2: 05-20: 15)$ \\
\hline
\end{tabular}


Table I: Sample characteristics (Continued)

\begin{tabular}{ll}
\hline Type of volatile anaesthetic $n(\%)$ & \\
\hline Isoflurane & $126(50.6 \%)$ \\
\hline Desflurane & $46(18.5 \%)$ \\
\hline Isoflurane + Sevoflurane & $32(12.9 \%)$ \\
\hline Sevoflurane & $22(8.8 \%)$ \\
\hline Isoflurane + Desflurane & $8(3.2 \%)$ \\
\hline Sevoflurane + Desflurane & $2(0.8 \%)$ \\
\hline Not recorded/not legible & $13(5.2 \%)$ \\
\hline Use of Nitrous Oxide** & $7(2.8 \%)$ \\
\hline Received Postoperative Anti-emetic (\%) & $199(79.9 \%)$ \\
\hline Opioid administration initiated by the first 24 hours (\%) & $228(91.6 \%)$ \\
\hline
\end{tabular}

*All but one child who received preoperative dexamethasone had a brain tumour.

**For induction only as no nitrous oxide was used for maintenance of anaesthesia.

for correlation of nominal variables $(\varphi)=.0 .65, \mathrm{p}<.001)$; thus, controlling for whether or not the child presented with vomiting proportionally decreased the odds of vomiting for children with brain tumours compared to those with Chiari I malformations. The combined surgery category of "other" was too small $(\mathrm{n}=15)$ to determine if there was similar effect. The odds ratio for hospital site changed to being significantly greater for the Hospital for Sick Children after the intraoperative variables were entered (Model 4). Desflurane and intraoperative ondansetron were used proportionately more at the Stollery Children's Hospital than at the Hospital for Sick Children $(69 \%$ vs. $9 \%$ for use of desflurane, $\varphi=0.59, p<.001$ and $62 \%$ vs. $43 \%$ for ondansetron, $\varphi=-0.16, p=.01$ ) There were no differences between the sites for the use of dexamethasone $(\varphi=0.08, p=.23)$ or length of surgery $(r$ $=-0.02 \mathrm{p}=.74)$. Thus, controlling for the combination of intraoperative risk factors, notably any use of desflurane and administration of intraoperative ondansetron, resulted in a proportionately higher reduction in the risk of vomiting by 120 hours at the Stollery Children's Hospital compared to the Hospital for Sick Children. These findings highlight the challenges that can be found in types of procedures and/or sites with different proportions of children exposed to potential risk and protective factors.

Table 2: Cumulative incidence of retching/vomiting, nausea and PONV

\begin{tabular}{|c|c|c|c|c|c|c|c|c|c|c|c|}
\hline & \multicolumn{11}{|c|}{$\begin{array}{l}\text { Hours from anaesthetic finish time } \\
\text { Total number of children with least one event recorded (Cumulative Percent) }\end{array}$} \\
\hline & $0-4$ & $0-8$ & $0-24$ & $0-48$ & $0-72$ & $0-96$ & $0-120$ & $0-144$ & $0-168$ & $0-192$ & $0-216^{*}$ \\
\hline Retching/Vomiting & $\begin{array}{l}59 \\
(23.7 \%)\end{array}$ & $\begin{array}{l}75 \\
(30.1 \%)\end{array}$ & $\begin{array}{l}119 \\
(47.8 \%)\end{array}$ & $\begin{array}{l}153 \\
(61.4 \%)\end{array}$ & $\begin{array}{l}164 \\
(65.9 \%)\end{array}$ & $\begin{array}{l}174 \\
(69.9 \%)\end{array}$ & $\begin{array}{l}181 \\
(72.7 \%)\end{array}$ & $\begin{array}{l}186 \\
(74.7 \%)\end{array}$ & $\begin{array}{l}187 \\
(75.1 \%)\end{array}$ & $\begin{array}{l}190 \\
(76.3 \%)\end{array}$ & $\begin{array}{l}191 \\
(76.7 \%)\end{array}$ \\
\hline Nausea $* *$ & $\begin{array}{l}24 \\
(9.6 \%)\end{array}$ & $\begin{array}{l}32 \\
(12.9 \%)\end{array}$ & $\begin{array}{l}59 \\
(23.7 \%)\end{array}$ & $\begin{array}{l}84 \\
(33.7 \%)\end{array}$ & $\begin{array}{l}93 \\
(37.3 \%)\end{array}$ & $\begin{array}{l}98 \\
(39.5 \%)\end{array}$ & $\begin{array}{l}103 \\
(41.4 \%)\end{array}$ & $\begin{array}{l}105 \\
(42.2 \%)\end{array}$ & $\begin{array}{l}105 \\
(42.2 \%)\end{array}$ & $\begin{array}{l}106 \\
(42.6 \%)\end{array}$ & $\begin{array}{l}107 \\
(43.0 \%)\end{array}$ \\
\hline PONV & $\begin{array}{l}69 \\
(27.7 \%)\end{array}$ & $\begin{array}{l}81 \\
(32.5 \%)\end{array}$ & $\begin{array}{l}134 \\
(53.8 \%)\end{array}$ & $\begin{array}{l}162 \\
(65.1 \%)\end{array}$ & $\begin{array}{l}172 \\
(69.1 \%)\end{array}$ & $\begin{array}{l}182 \\
(73.1 \%)\end{array}$ & $\begin{array}{l}189 \\
(75.9 \%)\end{array}$ & $\begin{array}{l}190 \\
(76.3 \%)\end{array}$ & $\begin{array}{l}191 \\
(76.7)\end{array}$ & $\begin{array}{l}194 \\
(77.9 \%)\end{array}$ & $\begin{array}{l}195 \\
(78.3 \%)\end{array}$ \\
\hline
\end{tabular}

PONV: First recorded nausea, retching or vomiting.

*No new recorded events after 216 hours.

***The differences between the incidence of nausea and retching/vomiting indicate that nausea is underestimated. 


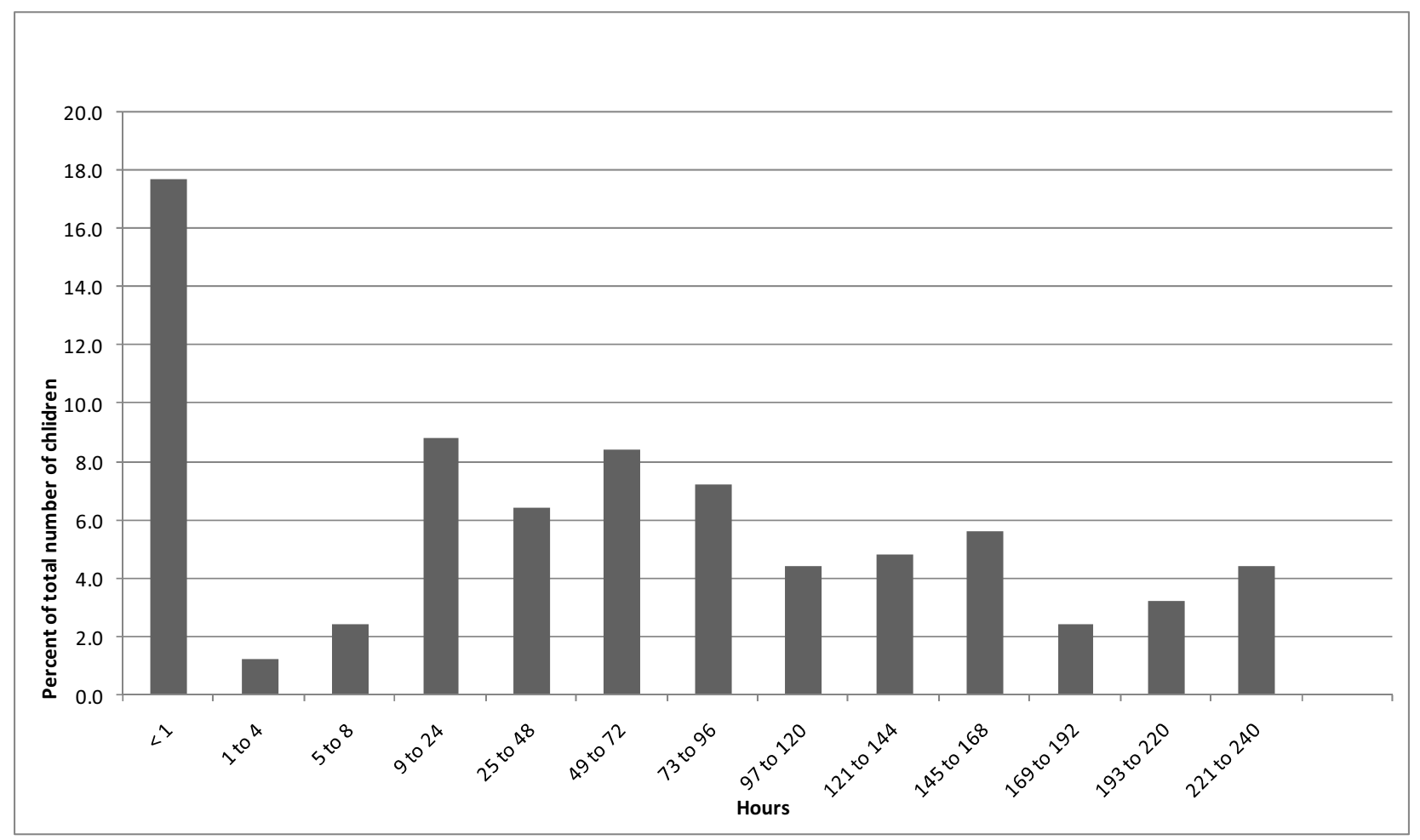

Figure 2

Hours from first recorded retching or vomiting to last in the $\mathbf{2 4 0}$ hours.

Finally, the addition of the interaction term of any use of desflurane and the administration of ondansetron (Model 5) also showed a change in the odds of POV by 120 hours for children requiring Chiari I surgery to a statistically significant result. However, there were no differences in the proportion of children in the three surgery categories who received both ondansetron and desflurane (13\% vs. $17 \%$ vs. $13 \%, \varphi=.06, p=.68)$. The interaction of intraoperative ondansetron and dexamethasone was not statistically significant when tested with this multivariable model.

The second multivariable modelling procedure (Table 5) was used to look at early (within 24 hours of their anaesthetic finish time) vs. late vomiting (after the first 24 hours up to 120 hours. The results of this analysis indicate that, controlling for the other variables in the model, children who received desflurane were more likely to begin vomiting within 24 hours of their anaesthetic finish time (early vomiting) than those who received one in the grouping of other volatile anaesthetics. Those in the two middle age quartiles (ages 4 to $<7$ and 7 to $<12$ ) were also more likely to start vomiting in the first 24 hours compared to those under age 4 and 12 to $<17$. There was no significant interaction between intraoperative administration of ondansetron and dexamethasone in this model either.
Assessment for multicollinearity (Table 6), showed no estimates with correlations above .80 . These results are suggestive that multicollinearity may not play a large role in the statistical model. The statistically significant correlations in this part of the statistical analysis correspond to the results already identified in the assessment for confounding effects (i.e., variables in a model that are related to each other and the outcome).

\section{Co-morbidities}

With the exception of infection, adverse events were frequently reported in the sample. Because posterior fossa syndrome is most commonly associated with brain tumours, the relationship between posterior fossa syndrome and POV by 120 hours was examined for brain tumours only. As shown in Table 7, there was no relationship between POV by 120 hours and the development of pseudomeningocele, wound failure or cerebral spinal fluid leak, infection, or posterior fossa syndrome.

\section{Discussion}

The results of this study support our clinical experience that POV is a common adverse outcome for children after posterior fossa surgery. Overall, POV is common enough to regard all children who require posterior fossa surgery as being at high risk for the development of POV. When 


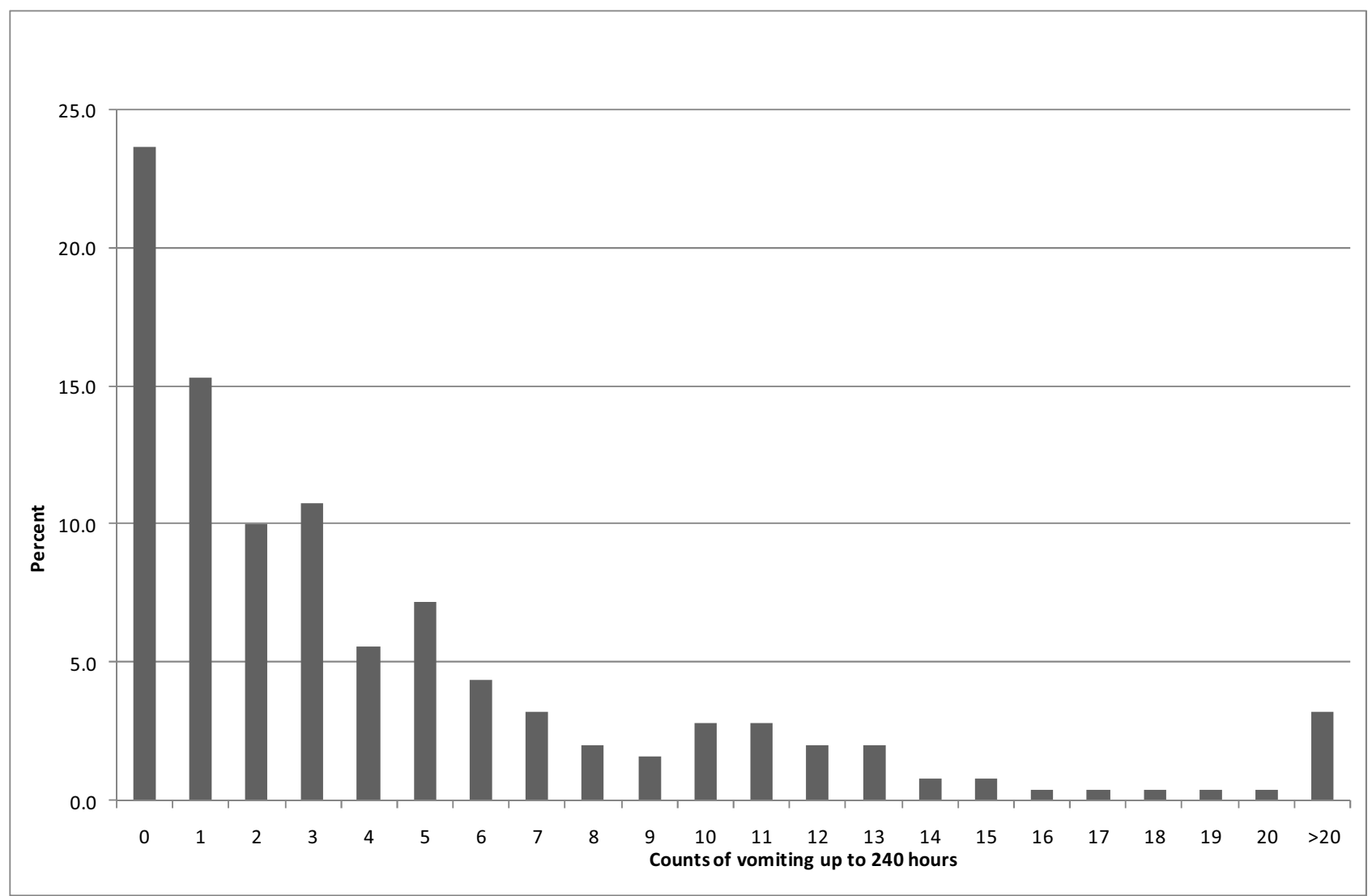

Figure 3

Number of recorded retching or vomiting events over the study period.

POV occurred, counts of vomiting events formed a positively skewed distribution in this sample. These results are similar to those shown by the data collected by Rowley and Brown [3] in their classic post-operative vomiting study of 1183 children after surgery. Many children in their sample experienced one or two episodes, with the number of events that a child experienced quickly tapering off. Rowley and Brown urged researchers to identify the recurrent, frequent, and distressing vomiting that fewer children experience but which results in significant distress and negative consequences for recovery. In this study, many children experienced greater than three events and/or experienced vomiting for time periods much longer than twenty four hours. This finding also has to be in the context of the use of intra-operative ondansetron for $47 \%$ of the children and use of postoperative antiemetics in $80 \%$ of the children. Thus, even with current efforts to prevent and treat POV, it was a frequent, recurrent and potentially long-lasting problem in this sample of children.

In this study, some variables were related to POV in children after posterior fossa surgery. These results may lead to the development of predictive tools or the identification of areas for stratification for future research. They will also help to identify challenges for future research, especially multi-site studies. That one hospital site showed greater odds of POV by 120 hours, once intraoperative variables were entered, highlights the difficulty in comparing between sites that may have varying intraoperative practices. Type of surgery was significant, with children requiring surgery for Chiari I Malformation more likely to have POV by 120 hours than children requiring brain tumour craniotomies and "other" procedures. Within the category of brain tumour surgery, there may be children who are at much higher risk for POV, balanced out by those at lower risk. A secondary analysis of these data for children with posterior fossa brain tumours, in particular, would be useful.

That the oldest age quartile ( 12 to $<17$ years) emerged as a protective factor for POV by 120 hours, once intraoperative variables were controlled for, is consistent with research in children following other types of surgery [27], but has not been supported in research for POV after craniotomy [11]. The two middle quartiles (ages 4 to $<12$ 
Table 3: Univariate analysis

\begin{tabular}{|c|c|c|}
\hline Variable & $\begin{array}{l}\text { POV by } 120 \text { Hours } \\
\text { Odds Ratio }(95 \% \mathrm{Cl})\end{array}$ & $\begin{array}{c}\text { Early ( } \leq 24 \text { hours) vs. } \\
\text { Late POVI } \\
\text { Odds Ratio }(95 \% \mathrm{Cl})\end{array}$ \\
\hline \multicolumn{3}{|l|}{ I. Site } \\
\hline Stollery Children's Hospital & 1.00 & 1.00 \\
\hline Hospital for Sick Children & $1.74(0.92-3.29)$ & $1.71(0.73-4.03)$ \\
\hline \multicolumn{3}{|l|}{ 2. Child Characteristics } \\
\hline \multicolumn{3}{|l|}{ Age } \\
\hline 0 to $<4$ years & 1.00 & 1.00 \\
\hline 4 to $<6$ years & $1.10(0.48-2.49)$ & $0.26(0.11-0.64)^{* *}$ \\
\hline 7 to $<12$ years & $0.90(0.42-1.92)$ & $0.30(0.13-0.69)^{* *}$ \\
\hline 12 to $<17$ years & $0.54(0.24-1.23)$ & $0.41(0.16-1.08)$ \\
\hline Female Gender & $0.79(0.45-1.38)$ & $1.39(0.74-2.62)$ \\
\hline \multicolumn{3}{|l|}{ Required Surgery } \\
\hline Brain Tumour & 1.00 & 1.00 \\
\hline Chiari I Malformation & $2.32(1.17-4.60)^{*}$ & $0.60(0.30-1.19)$ \\
\hline Other & $0.39(0.13-1.13)$ & $4.86(0.90-26.30)$ \\
\hline \multicolumn{3}{|l|}{ 3. Presenting Symptom } \\
\hline Presenting with Vomiting & $0.95(0.55-1.67)$ & $1.09(0.58-2.05)$ \\
\hline \multicolumn{3}{|l|}{ 4. Intraoperative Care } \\
\hline Administration of Ondansetron & $1.78(1.00-3.15)$ & $0.74(0.39-1.38)$ \\
\hline Administration of Dexamethasone & $0.65(0.37-1.15)$ & $1.62(0.86-3.05)$ \\
\hline Length of surgery & $1.00(0.98-1.01)$ & $1.00(0.98-1.01)$ \\
\hline Use of Desflurane & $1.32(0.66-2.64)$ & $0.34(0.14-0.83)^{*}$ \\
\hline $\begin{array}{l}\text { 5. Test of Interaction: Ondansetron and } \\
\text { Dexamethasone }\end{array}$ & $\begin{array}{l}\text { Adjusted Odds Ratio } \\
(95 \% \mathrm{Cl})\end{array}$ & $\begin{array}{c}\text { Adjusted Odds Ratio } \\
(95 \% \mathrm{Cl})\end{array}$ \\
\hline \multicolumn{3}{|l|}{ Step I } \\
\hline Intraoperative ondansetron & $1.92(1.07-3.45)^{*}$ & $1.75(1.91-3.35)$ \\
\hline Intraoperative dexamethasone & $0.59(0.33-1.06)$ & $0.66(0.34-1.26)$ \\
\hline
\end{tabular}

Step 2 
Table 3: Univariate analysis (Continued)

\begin{tabular}{|c|c|c|}
\hline Intraoperative ondansetron & $1.43(0.58-3.53)$ & $0.37(0.13-1.03)$ \\
\hline Intraoperative dexamethasone & $0.49(0.23-1.02)$ & $1.10(0.45-2.67)$ \\
\hline Dexamethasone $X$ ondansetron & $1.63(0.50-5.30)$ & $2.86(0.73-11.13)$ \\
\hline $\begin{array}{l}\text { Early vomiting coded as } 0 \text { and late } \\
<.05 \\
P<.01 \\
=\text { Confidence Interval }\end{array}$ & $n=|8|$ & \\
\hline
\end{tabular}

years) were more likely to vomit earlier, but their odds of vomiting were no different than those under four years of age by 120 hours. Infants and young children in this group of children may present later with vomiting and "catch-up" to school aged children by 120 hours. This result points to the importance of examining POV beyond the first 24 hours and continuing prophylactic use of antiemetics beyond 24 hours in at-risk groups. Interestingly, gender was not shown to be a significant risk factor and, therefore, an interaction effect of gender and age was not examined, despite the idea that females after puberty may be at higher risk for POV [27].

While not desflurane was commonly used in this sample, any use of desflurane was identified as a risk factor for early vomiting compared to the use of other volatile anaesthetics. This finding must be taken in the context of a small sample size and very wide confidence intervals when all other variables in the model were controlled for. The Stollery Children's Hospital site had a greater proportion of exposed children than the Hospital for Sick Children and the influence of individual clinicians was not accounted for. As previously discussed, the use of desflurane has been identified as a significant risk factor when compared to other volatile anaesthetics in a multivariable analysis of risk factors for PONV for adults requiring microvascular decompression of cranial nerves [20]; this is why we chose to include it, and compare it to a grouping of other volatile anaesthetics (isoflurane, sevoflurane and combinations of these) in the multivariable analysis. The use of desflurane in children has the advantage of rapid recovery [28] which must be clinically balanced with any potential disadvantages in this clinical population if chosen; however, its association with POV in this study warrants reconsideration of its use when there are other efficacious anesthetic options.

Children who received intraoperative ondansetron were more likely to vomit by 120 hours those who did not. This finding may be due to use of clinical judgment in administering ondansetron, a drug which has not been shown to have efficacy in preventing vomiting in children after craniotomy $[6,11]$. Thus, the administration of the drug was predictive of vomiting due to its administration to those correctly judged likely to vomit due to influences not measured or included in the multivariable analysis. Apfel and colleagues [4] also did not find a significant effect for intraoperative anti-emetics in decreasing POV in their multivariable logistic regression models. Interesting is the significant moderating effect of the intraoperative ondansetron on the use of desflurane as shown by the significant interaction term in the first multivariable model. Future studies of the efficacy of ondansetron, and other 5$\mathrm{HT}_{3}$ receptor antagonists, in preventing POV in this group of children might then include stratification for characteristics of the volatile anaesthetic used.

The intraoperative use of dexamethasone was not shown to be a protective factor for POV by 120 hours. Like ondansetron, its use may have been targeted to children clinically perceived to be at high risk for POV, and so a protective effect might not emerge in a retrospective study. The lack of significance of the use of intraoperative dexamethasone and the lack of an interaction effect between dexamethasone and ondansetron may also be reflective of this limitation. Additionally, we did not control for the use of preoperative dexamethasone because preoperative dexamethasone was given to most of the children with brain tumours, and thus collinearity with the type of surgery would be a problem. However, Subramaniam and colleagues [11] did look at preoperative dexamethasone treatment in children with brain tumours in their randomized controlled trial of ondansetron. These authors found no difference in PONV between children who received dexamethasone preoperatively and those who did not. Length of surgery as a continuous variable was also not a significant risk factor for POV by 120 hours in this sample, which is consistent with previous research, where the cut off for a protective effect for length of surgery was 30 minutes $[3,9]$.

Finally, associations between POV by 120 hours and a number of negative consequences for recovery - the development of a pseudomeningocele, infection, wound failure/cerebral spinal fluid leak, and posterior fossa syndrome (in children with brain tumours) - could not 
Table 4: Multivariable analysis: POV by $I 20$ hours

\begin{tabular}{|c|c|c|c|c|c|}
\hline Model Number & 5 & 4 & 3 & 2 & 1 \\
\hline Variable & $\begin{array}{c}\text { Adjusted Odds Ratio } \\
(95 \% \mathrm{Cl})\end{array}$ & $\begin{array}{c}\text { Adjusted Odds Ratio } \\
(95 \% \mathrm{Cl})\end{array}$ & $\begin{array}{c}\text { Adjusted Odds Ratio } \\
(95 \% \mathrm{Cl})\end{array}$ & $\begin{array}{c}\text { Adjusted Odds Ratio } \\
(95 \% \mathrm{Cl})\end{array}$ & $\begin{array}{l}\text { Odds Ratio } \\
(95 \% \mathrm{Cl})\end{array}$ \\
\hline \multicolumn{6}{|l|}{ I. Site } \\
\hline Stollery Children's Hospital & 1.00 & 1.00 & 1.00 & 1.00 & 1.00 \\
\hline Hospital for Sick Children & $\begin{array}{c}3.92 \\
(1.45-10.58)^{*}\end{array}$ & $\begin{array}{c}4.25 \\
(1.62-11.12)^{\alpha * *}\end{array}$ & $\begin{array}{c}1.78 \\
(0.90-3.51)\end{array}$ & $\begin{array}{c}1.78 \\
(0.90-3.50)\end{array}$ & $\begin{array}{c}1.74 \\
(0.92-3.29)\end{array}$ \\
\hline
\end{tabular}

2. Child Characteristics

\begin{tabular}{|c|c|c|c|c|}
\hline Age in quartiles\% & & & & \\
\hline 0 to $<4$ years & 1.00 & 1.00 & 1.00 & 1.00 \\
\hline 4 to $<7$ years & $\begin{array}{c}0.86 \\
(0.35-2.14)\end{array}$ & $\begin{array}{c}0.84 \\
(0.34-2.06)\end{array}$ & $\begin{array}{c}0.96 \\
(0.4 I-2.27)\end{array}$ & $\begin{array}{c}1.00 \\
(0.43-2.35)\end{array}$ \\
\hline 7 to $<12$ years & $\begin{array}{c}0.51 \\
(0.21-1.22)\end{array}$ & $\begin{array}{c}0.56 \\
(0.24-1.31)\end{array}$ & $\begin{array}{c}0.72 \\
(0.32-1.6 I)\end{array}$ & $\begin{array}{c}0.74 \\
(0.33-1.64)\end{array}$ \\
\hline 12 to $<17$ years & $\begin{array}{c}0.34 \\
(0.13-0.88)^{*}\end{array}$ & $\begin{array}{c}0.33 \\
(0.13-0.82)^{\alpha *}\end{array}$ & $\begin{array}{c}0.48 \\
(0.20-1.12)\end{array}$ & $\begin{array}{c}0.47 \\
(0.20-1.11)\end{array}$ \\
\hline Female Gender & $\begin{array}{c}0.64 \\
(0.34-2.14)\end{array}$ & $\begin{array}{c}0.66 \\
(0.35-1.2 I)\end{array}$ & $\begin{array}{c}0.71 \\
(0.39-1.27)\end{array}$ & $\begin{array}{c}0.69 \\
(0.39-1.25)\end{array}$ \\
\hline \multicolumn{5}{|l|}{ Surgery } \\
\hline Brain Tumour & 1.00 & 1.00 & 1.00 & 1.00 \\
\hline Chiari I Malformation & $\begin{array}{c}2.78 \\
(1.03-7.50)^{*}\end{array}$ & $\begin{array}{c}2.43 \\
(0.9 I-6.48)^{\alpha}\end{array}$ & $\begin{array}{c}3.46 \\
(1.48-8.10)^{\alpha * * *}\end{array}$ & $\begin{array}{c}2.80 \\
(1.37-5.7 \mid)^{* * *}\end{array}$ \\
\hline Other & $\begin{array}{c}0.65 \\
(0.31-1.35)\end{array}$ & $\begin{array}{c}0.53 \\
(0.14-1.99)\end{array}$ & $\begin{array}{c}0.54 \\
(0.17-1.79)\end{array}$ & $\begin{array}{c}0.44 \\
(0.15-1.35)\end{array}$ \\
\hline \multicolumn{5}{|l|}{ 3. Presenting Symptoms } \\
\hline Presenting with Vomiting & $\begin{array}{c}1.75 \\
(0.79-3.91)\end{array}$ & $\begin{array}{c}1.63 \\
(0.75-3.54)\end{array}$ & $\begin{array}{c}1.40 \\
(0.67-2.90)\end{array}$ & \\
\hline \multicolumn{5}{|l|}{ 4. Intraoperative Care } \\
\hline Administration of Ondansetron & $\begin{array}{c}3.47 \\
(1.61-7.47)^{* *}\end{array}$ & $\begin{array}{c}2.22 \\
(1.14-4.33)^{*}\end{array}$ & & \\
\hline Administration of Dexamethasone & $\begin{array}{c}0.65 \\
(0.31-1.35)\end{array}$ & $\begin{array}{c}0.58 \\
(0.28-1.19)\end{array}$ & & \\
\hline Length of surgery & $\begin{array}{c}0.90 \\
(.76-1.06)\end{array}$ & $\begin{array}{c}0.91 \\
(0.78-1.08)\end{array}$ & & \\
\hline Use of Desflurane & $\begin{array}{c}14.08 \\
(2.47-80.32)^{* *}\end{array}$ & $\begin{array}{c}3.11 \\
(1.13-8.62)^{*}\end{array}$ & & \\
\hline
\end{tabular}


Table 4: Multivariable analysis: POV by 120 hours (Continued)

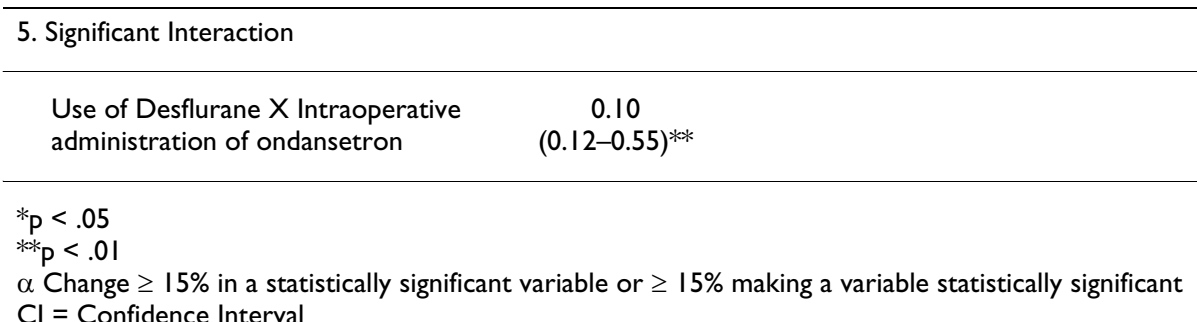

be identified in the data. These outcomes may be better studied prospectively with consideration of the severity of POV. A prospective study would also aid in identifying a causal pathway in the relationship between negative outcomes and POV.

The primary limitation of this study is its retrospective nature as it limits the researchers' control over the data that can be collected. For the outcomes of nausea, vomiting, and retching, the quality of the charting by health care professionals was paramount. The exact count of vomiting episodes was likely underestimated, as severe events were often identified as "+ + + vomiting," but the cumulative incidence of vomiting at the specified time period should be accurate. Additionally, retching may have only been charted if it occurred without vomiting, for example in the post-anaesthesia recovery room or paediatric intensive care. Once the child was cared for in the general nursing care unit, it may have been unobserved by the health care team and thus not documented. Subjective measures of nausea, expressed by the child, were rarely charted. In adults after craniotomy, risk factors for nausea may be different than those for vomiting [7]. As we were unable to evaluate risk and protective factors for nausea, the results of this study can not be applied to PON.

There were also challenges in conducting the study at two sites. Differences in the way that postoperative neurosurgical care was provided and the timing of transfer of the child either home, for rehabilitation, or for oncology treatment, varied between institutions. Different documentation styles and charting practices may have also affected data collection. Defining what constituted the acute postoperative period was also difficult and the outcomes for analysis of risk and protective factors were decided once the data were collected and descriptive statistics completed.

Sample size issues also became apparent in the final stages of the multivariable analysis, as shown by the wide confidence intervals for some variables. Initially we had estimated a sample size of approximately 300. There were more children with exclusion criteria than expected, which decreased the final sample. The high incidence of vomiting, even when the outcome was limited to POV by 120 hours, resulted in five children without vomiting per variable for the final multivariable model. Therefore, the results of the multivariable analysis should be interpreted with caution and require further validation.

Due to the retrospective nature of the data collection, the multivariable models developed in this study can be used to identify risk and protective factors for POV in children after posterior fossa surgery in general. The models were not developed for prognosis or risk scoring at the individual level. The study does not show the effect of treatments, only their contribution as possible risk or protective factors. The type of data that can be extracted is limited to what is charted in a retrospective study. For example, whether or not the administration of a postoperative antiemetic was prophylactic or therapeutic could not be reliably determined and therefore was not used in the analysis. A further limitation of the study is that the outcomes examined for the risk and protective factors were one or more events of POV by 120 hours and early vs. late POV. Severity of POV, an important outcome that is often clinically observed in children after posterior fossa surgery, and may be inferred from the frequency of events and length of time that POV was experienced, was not quantified for the analysis of risk and protective factors.

\section{Conclusion}

The findings of risk and protective factors in this study support the suggestion that current prognostic models and risk scoring systems for POV should not be used in children after posterior fossa craniotomy [29] as they may be different for this population. Given the descriptive findings of how common POV is in this group of children after posterior fossa surgery, guidelines such as those proposed by The Society for Ambulatory Anesthesia [30] for POV in high risk populations should be considered. These guidelines include the use of two or three prophylactic drugs from different classes for children who are at high risk for POV and to consider the use of total intravenous anaesthesia (TIVA). With established POV, drugs from another class than that already in use ought to be considered. Importantly, in a Bayesian Meta-analysis of six single drugs and five combinations, Engelman, Salengaros, and Barvais [31] found the greatest relative risk reduction $(80 \%)$ in POV with the combination of the $5-\mathrm{HT}_{3}$ receptor antagonists and dexamethasone. Of particular note, is the current absence of evidence that any class of drug, includ- 
Table 5: Multivariable analysis: Early vs. late POV (POV in the first 24 hours vs. after 24 hours to I 20 hours)'

\begin{tabular}{|c|c|c|c|c|}
\hline Model Number & 4 & 3 & 2 & 1 \\
\hline Variable & $\begin{array}{c}\text { Adjusted Odds Ratio } \\
(95 \% \mathrm{Cl})\end{array}$ & $\begin{array}{c}\text { Adjusted Odds Ratio } \\
(95 \% \mathrm{Cl})\end{array}$ & $\begin{array}{c}\text { Adjusted Odds Ratio } \\
(95 \% \mathrm{Cl})\end{array}$ & $\begin{array}{l}\text { Odds Ratio } \\
(95 \% \mathrm{Cl})\end{array}$ \\
\hline \multicolumn{5}{|l|}{ I. Site } \\
\hline Stollery Children's Hospital & 1.00 & 1.00 & 1.00 & 1.00 \\
\hline Hospital for Sick Children & $\begin{array}{c}0.72 \\
(0.22-2.19)\end{array}$ & $\begin{array}{c}1.80 \\
(0.72-4.52)\end{array}$ & $\begin{array}{c}1.80 \\
(0.72-4.50)\end{array}$ & $\begin{array}{c}1.71 \\
(0.72-4.03)\end{array}$ \\
\hline
\end{tabular}

2. Child Characteristics

\begin{tabular}{|c|c|c|c|}
\hline Age in quartiles\% & & & \\
\hline 0 to $<4$ years & 1.00 & 1.00 & 1.00 \\
\hline 4 to $<7$ years & $\begin{array}{c}0.30 \\
(0.11-0.79) *\end{array}$ & $\begin{array}{c}0.31 \\
(0.12-0.79)^{*}\end{array}$ & $\begin{array}{c}0.31 \\
(0.12-0.78)^{*}\end{array}$ \\
\hline 7 to $<12$ years & $\begin{array}{c}0.31 \\
(0.13-0.79)^{*}\end{array}$ & $\begin{array}{c}0.32 \\
(0.13-0.77)^{*}\end{array}$ & $\begin{array}{c}0.32 \\
(0.13-0.76)^{*}\end{array}$ \\
\hline 12 to $<17$ years & $\begin{array}{c}0.50 \\
(0.17-1.48)\end{array}$ & $\begin{array}{c}0.47 \\
(0.17-1.30)\end{array}$ & $\begin{array}{c}0.47 \\
(0.17-1.29)\end{array}$ \\
\hline Female Gender & $\begin{array}{c}1.90 \\
(0.93-3.91)\end{array}$ & $\begin{array}{c}1.62 \\
(0.8 I-3.2 I)\end{array}$ & $\begin{array}{c}1.62 \\
(0.82-3.21)\end{array}$ \\
\hline \multicolumn{4}{|l|}{ Required Surgery } \\
\hline Brain Tumour & 1.00 & 1.00 & 1.00 \\
\hline Chiari I Malformation & $\begin{array}{c}0.64 \\
(0.22-1.88)\end{array}$ & $\begin{array}{c}0.64 \\
(0.20-1.38)\end{array}$ & $\begin{array}{c}0.57 \\
(0.27-1.20)\end{array}$ \\
\hline Other & $\begin{array}{c}2.82 \\
(0.39-20.70)\end{array}$ & $\begin{array}{c}2.63 \\
(0.40-16.19)\end{array}$ & $\begin{array}{c}2.70 \\
(0.45-16.14)\end{array}$ \\
\hline \multicolumn{4}{|l|}{ 3. Presenting Symptom } \\
\hline Presenting with Vomiting & $\begin{array}{c}0.71 \\
(0.26-1.84)\end{array}$ & $\begin{array}{c}0.89 \\
(0.36-2.17)\end{array}$ & \\
\hline \multicolumn{4}{|l|}{ 4. Intraoperative Care } \\
\hline Administration of Ondansetron & $\begin{array}{c}0.85 \\
(0.40-1.80)\end{array}$ & & \\
\hline Administration of Dexamethasone & $\begin{array}{c}2.02 \\
(0.87-4.68)\end{array}$ & & \\
\hline Length of surgery & $\begin{array}{c}1.00 \\
(0.98-1.02)\end{array}$ & & \\
\hline Use of Desflurane & $\begin{array}{c}0.23 \\
(0.07-0.73)^{*}\end{array}$ & & \\
\hline
\end{tabular}

I. Early vomiting coded as 0 and late vomiting coded as $I, n=181$.

$* \mathrm{p}<.05 * * \mathrm{p}<.01$

$\alpha$ Change $\geq 15 \%$ in a statistically significant variable or $\geq 15 \%$ making a variable statistically significant $\mathrm{Cl}=$ Confidence Interval 
Table 6: Correlations among independent variables in the model

\begin{tabular}{|c|c|c|c|c|c|c|c|c|c|c|c|c|c|}
\hline Variable & & I & 2 & 3 & 4 & 5 & 6 & 7 & 8 & 9 & 10 & II & 12 \\
\hline Site & I & 1.00 & & & & & & & & & & & \\
\hline 4 to $<6$ years ${ }^{\prime}$ & 2 & -.06 & 1.00 & & & & & & & & & & \\
\hline 7 to $<12$ years 1 & 3 & .16 & - & 1.00 & & & & & & & & & \\
\hline 12 to $<17$ years 1 & 4 & -.08 & - & - & 1.00 & & & & & & & & \\
\hline Female & 5 & -.03 & -.03 & .03 & .03 & 1.00 & & & & & & & \\
\hline Chiari I Malformation² & 6 & -.04 & -.02 & .01 & .10 & .15 & 1.00 & & & & & & \\
\hline Other $^{2}$ & 7 & -.07 & -.07 & -.09 & .09 & -.01 & - & 1.00 & & & & & \\
\hline Presenting with Vomiting & 8 & .05 & .11 & .04 & -.15 & -.13 & $-.57^{*}$ & $-.20 *$ & 1.00 & & & & \\
\hline Administration of Ondansetron & 9 & -.16 & .01 & .10 & .11 & .06 & .03 & -.10 & .03 & 1.00 & & & \\
\hline Administration of Dexamethasone & 10 & .08 & .09 & -.01 & -.09 & -.03 & $-.46^{*}$ & -.10 & $.40^{*}$ & .14 & 1.00 & & \\
\hline Length of surgery & II & .08 & .09 & -.01 & -.09 & -.02 & $.45^{*}$ & -.10 & $-.39 *$ & .14 & $.30 *$ & 1.00 & \\
\hline Use of Desflurane & 12 & -.59 & .01 & -.12 & -.13 & .07 & .04 & -.02 & -.08 & .19 & .03 & .00 & 1.00 \\
\hline
\end{tabular}

I. Reference category $0-<4$

2. Reference category brain tumour surgery $*$ Two tailed $p<.0$ I

Table 7: Relationship of POV by 120 hours to adverse outcomes

\begin{tabular}{|c|c|c|c|}
\hline \multirow[b]{2}{*}{ Total $(n=249)$} & \multicolumn{2}{|c|}{$\begin{array}{c}\text { Vomiting by } 120 \text { hours } \\
\text { n (\% total) }\end{array}$} & \multirow[t]{2}{*}{$\begin{array}{l}\text { Phi Statistic } \\
\text { (Significance) }\end{array}$} \\
\hline & No & Yes & \\
\hline \multicolumn{4}{|c|}{ Pseudomeningocele } \\
\hline No & $49(19.7)$ & $124(49.8)$ & \\
\hline Yes & $19(7.6)$ & $57(22.9)$ & $0.03(p=.59)$ \\
\hline \multicolumn{4}{|c|}{ Would Failure/CSF Leak } \\
\hline No & $55(22.1)$ & $158(63.5)$ & \\
\hline Yes & $13(5.2)$ & $23(9.2)$ & $-0.08(p=.20)$ \\
\hline \multicolumn{4}{|c|}{ Wound Infection } \\
\hline No & $63(25.3)$ & $175(70.3)$ & \\
\hline Yes & $5(2.0)$ & $6(2.4)$ & $-0.09(p=.17)$ \\
\hline \multicolumn{4}{|c|}{ Brain Tumour $(n=153)$} \\
\hline \multicolumn{4}{|c|}{ Posterior Fossa Syndrome } \\
\hline No & $34(22.2)$ & $82(53.6)$ & \\
\hline Yes & $13(8.5)$ & $24(15.7)$ & $-0.05(p=.50)$ \\
\hline
\end{tabular}


ing the combination of dexamethasone and ondansetron, is effective for preventing or treating POV in children after craniotomy. Overall, this is a unique but understudied population of children who are at risk for POV.

There have also not been any studies of particular anaesthetic protocols, such as TIVA with propofol, in children requiring posterior fossa surgery. Knowledge and treatment guidelines are currently limited to what is known in other patient populations. Translating current knowledge and treatment guidelines to children requiring posterior fossa surgery is challenging. For example, even the results of studies of TIVA in adults after craniotomy remain inconclusive [32]. Finally, given the length of time that children experience POV, it is necessary that protocols for inpatient anti-emetic care, including length of time postoperative dexamethasone is administered and the postoperative use of intermittent use of anti-emetics, be developed and tested in children requiring posterior fossa craniotomy. Ultimately, a methodical approach to preventing and treating POV, starting in the preoperative period, following through the child's course of care in the hospital and included in discharge planning, is required for this vulnerable group of children.

\section{Competing interests}

The authors declare that they have no competing interests.

\section{Authors' contributions}

SN Conceptualized the study, collected data at the Stollery Children's Hospital Site, entered and analyzed the data, and drafted the manuscript, revised and prepared the manuscript for publication. CNC Helped with the study design and methodology, critically revised the manuscript and approved the final version for publication. DS Developed the statistical plan for the manuscript, directed the statistical analysis and interpretation of the data, and critically revised the statistical portion of the manuscript. BD Helped with the conceptualization of the study, collected data at the Hospital for Sick Children, critically revised the manuscript and reviewed the final version for publication. HY Helped conceptualize the study, assisted in the development of the data collection tool, and was study coordinator at the Hospital for Sick Children. JD Helped with conceptualization of the study, critically revised the manuscript, and approved the final version for publication. All authors read and approved the final version of the manuscript.

\section{Authors' information}

$\mathrm{SM}, \mathrm{BD}$, and $\mathrm{HY}$ are nurses who work in children's neurosurgery, where their clinical experience prompted them to identify the extent of postoperative nausea and vomiting on their units, not only to gain knowledge of the problem but to then identify ways to help these children and their families.

\section{Acknowledgements}

This study was sponsored by a seed funding grant from the Pediatric Oncology Group of Ontario (POGO). SN was supported by a Strategic Training Fellowship from the Canadian Child Health Clinician Scientist Program and an Honorary Doctoral Award from the Killam Foundation.

We want to acknowledge Dr. Keith Aronyk and Dr. Vivek Mehta for clinical advice and Donald James for data entry.

\section{References}

I. Scuderi PE, Conlay LA: Postoperative nausea and vomiting and outcome. Int Anesthesiol Clin 2003, 4 I (4): I 65- 174.

2. Macario A, Weinger M, Carney S, Kim A: Which clinical anesthesia outcomes are important to avoid? The perspective of patients. Anesth Analg 1999, 89(3):652-658.

3. Rowley MP, Brown TC: Postoperative vomiting in children. Anaesth Intensive Care 1982, I0(4):309-313.

4. Apfel CC, Kranke P, Katz MH, Goepfert C, Papenfuss T, Rauch S, Heineck R, Greim CA, Roewer N: Volatile anaesthetics may be the main cause of early but not delayed postoperative vomiting: a randomized controlled trial of factorial design. Br J Anaesth 2002, 88(5):659-668.

5. Rose JB, Watcha MF: Postoperative nausea and vomiting in paediatric patients. Br J Anaesth 1999, 83(I): 104-II7.

6. Furst SR, Sullivan LJ, Soriano SG, McDermott JS, Adelson PD, Rockoff MA: Effects of ondansetron on emesis in the first 24 hours after craniotomy in children. Anesth Analg 1996, 83(2):325-328.

7. Fabling JM, Gan TJ, Guy J, Borel CO, el-Moalem HE, Warner DS: Postoperative nausea and vomiting. A retrospective analysis in patients undergoing elective craniotomy. J Neurosurg Anesthesiol 1997, 9(4):308-312.

8. Tramer MR: [Prevention and treatment of postoperative nausea and vomiting in children. An evidence-based approach]. Ann Fr Anesth Reanim 2007, 26(6):529-534.

9. Eberhart LH, Geldner G, Kranke P, Morin AM, Schauffelen A, Treiber $\mathrm{H}$, Wulf $\mathrm{H}$ : The development and validation of a risk score to predict the probability of postoperative vomiting in pediatric patients. Anesth Analg 2004, 99(6): 1630-1637.

10. Kranke P, Eberhart LH, Toker H, Roewer N, Wulf H, Kiefer P: A prospective evaluation of the POVOC score for the prediction of postoperative vomiting in children. Anesth Analg 2007, 105(6): 1592-1597.

II. Subramaniam K, Pandia MP, Dash M, Dash HH, Bithal PK, Bhatia A, Subramaniam B: Scheduled prophylactic ondansetron administration did not improve its antiemetic efficacy after intracranial tumour resection surgery in children. European Journal of Anaesthesiology 2007, 24(7):615-619.

12. Hornby PJ: Central neurocircuitry associated with emesis. Am J Med 200I, I I I(Suppl 8A): I06S-I I 2S.

13. Miller AD: Central mechanisms of vomiting. Dig Dis Sci 1999, 44(8 Suppl):39S-43S.

14. Miller AD, Nonaka S, Jakus J, Yates BJ: Modulation of vomiting by the medullary midline. Brain Res 1996, 737(I-2):5I-58.

15. Manninen PH, Tan TK: Postoperative nausea and vomiting after craniotomy for tumor surgery: a comparison between awake craniotomy and general anesthesia. J Clin Anesth 2002, I4(4):279-283.

16. Kurita N, Kawaguchi M, Nakahashi K, Sakamoto N, Horiuchi T, Takahashi M, Kitaguchi K, Furuya H: Retrospective Analysis of Postoperative Nausea and Vomiting after Craniotomy. Masui Japanese Journal of Anesthesiology 2004, 53(2): I50- I55.

17. Gottschalk A, Berkow LC, Stevens RD, Mirski M, Thompson RE, White ED, Weingart JD, Long DM, Yaster M: Prospective evaluation of pain and analgesic use following major elective intracranial surgery. J Neurosurg 2007, 106(2):210-216.

18. Quiney N, Cooper R, Stoneham M, Walters F: Pain after craniotomy. A time for reappraisal? BrJ Neurosurg 1996, I 0(3):295-299.

19. Flynn BC, Nemergut EC: Postoperative nausea and vomiting and pain after transsphenoidal surgery: a review of $\mathbf{8 7 7}$ patients. Anesth Analg 2006, 103(1):162-167.

20. Meng L, Quinlan J]: Assessing risk factors for postoperative nausea and vomiting: a retrospective study in patients undergoing retromastoid craniectomy with microvascular 
decompression of cranial nerves. J Neurosurg Anesthesiol 2006, 18(4):235-239.

21. Stieglitz LH, Samii A, Kaminsky J, Gharabaghi A, Samii M, Ludemann WO: Nausea and dizziness after vestibular schwannoma surgery: a multivariate analysis of preoperative symptoms. Neurosurgery 2005, 57(5):887-890.

22. Lenth RV: Piface I.64 edition. 2006.

23. Peduzzi P, Concato J, Kemper E, Holford TR, Feinstein AR: A simulation study of the number of events per variable in logistic regression analysis. J Clin Epidemiol 1996, 49( I 2): | 373-I379.

24. Gan TJ: Risk factors for postoperative nausea and vomiting. Anesth Analg 2006, 102(6): 1884-1898.

25. Apfel CC, Roewer N, Korttila K: How to study postoperative nausea and vomiting. Acta Anaesthesiol Scand 2002, 46(8):92I-928.

26. Korttila $\mathrm{K}:$ The study of postoperative nausea and vomiting. BrJ Anaesth 1992, 69(7 Suppl I):20S-23S.

27. Kovac AL: Management of postoperative nausea and vomiting in children. Paediatr Drugs 2007, 9(1):47-69.

28. Lerman J: Inhalation agents in pediatric anaesthesia - an update. Curr Opin Anaesthesiol 2007, 20(3):22I-226.

29. Neufeld SM, Drummond J, Newburn-Cook CV: Prognostic models and risk scores: Can we accurately predict postoperative vomiting for children after craniotomy. Journal of Perianesthesia Nursing 2008, 23(5):300-310.

30. Gan T], Meyer TA, Apfel CC, Chung F, Davis PJ, Habib AS, Hooper VD, Kovac AL, Kranke P, Myles P, et al.: Society for Ambulatory Anesthesia guidelines for the management of postoperative nausea and vomiting. Anesth Analg 2007, 105(6): 16I5-1628.

31. Engelman E, Salengros JC, Barvais L: How much does pharmacologic prophylaxis reduce postoperative vomiting in children? Calculation of prophylaxis effectiveness and expected incidence of vomiting under treatment using Bayesian metaanalysis. Anesthesiology 2008, 109(6): 1023-1035.

32. Pasternak JJ, Lanier WL: Neuroanesthesiology review - 2007. J Neurosurg Anesthesiol 2008, 20(2):78-104.

\section{Pre-publication history}

The pre-publication history for this paper can be accessed here:

http://www.biomedcentral.com/1472-6955/8/7/prepub

Publish with Biomed Central and every scientist can read your work free of charge

"BioMed Central will be the most significant development for disseminating the results of biomedical research in our lifetime. "

Sir Paul Nurse, Cancer Research UK

Your research papers will be:

- available free of charge to the entire biomedical community

- peer reviewed and published immediately upon acceptance

- cited in PubMed and archived on PubMed Central

- yours - you keep the copyright
BioMedcentral 